Article

\title{
Psychological Distress in Men during the COVID-19 Pandemic in Brazil: The Role of the Sociodemographic Variables, Uncertainty, and Social Support
}

\author{
Anderson Reis de Sousa ${ }^{1}$, Jules Ramon Brito Teixeira ${ }^{2}$ D, Emanuel Missias Silva Palma ${ }^{3}$, \\ Wanderson Carneiro Moreira ${ }^{4,5}$, Milena Bitencourt Santos ${ }^{1}$ (D), Herica Emilia Félix de Carvalho ${ }^{6}$, \\ Éric Santos Almeida ${ }^{1}{ }^{(D}$, Raíssa Millena Silva Florencio ${ }^{7}{ }^{(D}$, Aline Macêdo de Queiroz ${ }^{8}$, \\ Magno Conceição das Merces ${ }^{9}$ (D), Tilson Nunes Mota ${ }^{10}$, Isabella Félix Meira Araújo ${ }^{1}$, Josielson Costa da Silva ${ }^{1}$ (D), \\ Sélton Diniz dos Santos ${ }^{2}$ (D) Emerson Lucas Silva Camargo ${ }^{11}\left(\mathbb{D}\right.$, Luciano Garcia Lourenção ${ }^{12}(\mathbb{D}$, \\ Richardson Augusto Rosendo da Silva ${ }^{13}$ (D), Evanilda Souza de Santana Carvalho ${ }^{2}$, Iracema Lua ${ }^{14}$, Sônia Barros 4 , \\ Tânia Maria de Araújo ${ }^{2}\left(\mathbb{D}\right.$, Márcia Aparecida Ferreira de Oliveira ${ }^{4,15} \mathbb{D}$, Álvaro Pereira ${ }^{1}$, Wilson Abreu ${ }^{16}$ (D) \\ and Carlos Alberto da Cruz Sequeira 16,*(D)
}

check for updates

Citation: de Sousa, A.R.; Teixeira, J.R.B.; Palma, E.M.S.; Moreira, W.C.; Santos, M.B.; de Carvalho, H.E.F.; Almeida, É.S.; Florencio, R.M.S.; de Queiroz, A.M.; Merces, M.C.d.; et al. Psychological Distress in Men during the COVID-19 Pandemic in Brazil: The Role of the Sociodemographic Variables, Uncertainty, and Social Support. Int. J. Environ. Res. Public Health 2022, 19, 350. https://doi.org/ 10.3390/ijerph19010350

Academic Editor: Paul B. Tchounwou

Received: 22 November 2021 Accepted: 18 December 2021 Published: 29 December 2021

Publisher's Note: MDPI stays neutral with regard to jurisdictional claims in published maps and institutional affiliations.

Copyright: (C) 2021 by the authors. Licensee MDPI, Basel, Switzerland. This article is an open access article distributed under the terms and conditions of the Creative Commons Attribution (CC BY) license (https:// creativecommons.org/licenses/by/ $4.0 /)$.
1 Escola de Enfermagem, Universidade Federal da Bahia, Salvador 40231-300, BA, Brazil; anderson.sousa@ufba.br (A.R.d.S.); milena_b.s@hotmail.com (M.B.S.); eriksdn@gmail.com (É.S.A.); isabellafelixmeira@hotmail.com (I.F.M.A.); josielson.silva@ufba.br (J.C.d.S.); alvaro_pereira_ba@yahoo.com.br (Á.P.)

2 Departamento de Saúde, Universidade Estadual de Feira de Santana, Feira de Santana 44001-970, BA, Brazil julesramon@gmail.com (J.R.B.T.); sdsantos@uefs.br (S.D.d.S.); evasscarvalho@uefs.br (E.S.d.S.C.); araujo.tania@uefs.br (T.M.d.A.)

3 Escola Bahiana de Medicina e Saúde Pública, Salvador 40290-000, BA, Brazil; emanuelmssilva@gmail.com

4 Escola de Enfermagem, Universidade de São Paulo, Sao Paulo 05403-000, SP, Brazil; wanderson.moreira@usp.br (W.C.M.); sobarros@usp.br (S.B.); marciaap@usp.br (M.A.F.d.O.)

5 Coordenação de Saúde do Adolescente, Jovem e Homem, Diretoria Técnica, Secretaria de Saúde, Prefeitura Municipal de Ananindeua, Ananindeua 67130-600, PA, Brazil

6 Escola de Enfermagem de Ribeirão Preto, Universidade de São Paulo, Ribeirao Preto 14040-902, SP, Brazil; hericacarvalho@usp.br

7 Faculdade Estácio de Alagoinhas, Alagoinhas 48010-970, BA, Brazil; raissaflorencio@yahoo.com.br

$8 \quad$ Faculdade de Enfermagem, Universidade Federal do Pará, Belem 66075-110, PA, Brazil; alinemacedo@ufpa.br

9 Departamento de Ciências da Vida, Universidade do Estado da Bahia, Salvador 1150-000, BA, Brazil; mmerces@uneb.br

10 Secretaria de Ciência, Tecnologia e Inovação, Salvador 41745-004, BA, Brazil; tilson.nunes.mota@gmail.com

11 Curso de Psicologia, Campus Ribeirão, Universidade de Ribeirão Preto, Ribeirao Preto 11440-003, SP, Brazil; lucmrg0@gmail.com

12 Escola de Enfermagem, Universidade Federal do Rio Grande, Rio Grande 96201-900, RS, Brazil; lucianolourencao.enf@gmail.com

13 Departamento de Enfermagem, Universidade Federal do Rio Grande do Norte, Natal 59012-300, RN, Brazil rirosendo@hotmail.com

14 Instituto de Saúde Coletiva, Universidade Federal da Bahia, Salvador 40110-040, BA, Brazil; ira_lua@hotmail.com

15 Programa de Pós-Graduação em Enfermagem, Centro de Ciências da Saúde, Universidade Federal de Santa Maria, Santa Maria 97105-900, RS, Brazil

16 Centro de Investigação em Tecnologias e Serviços de Saúde, Escola Superior de Enfermagem do Porto, 4200-072 Porto, Portugal; wjabreu@esenf.pt

* Correspondence: carlossequeira@esenf.pt

\begin{abstract}
Objective: To analyze the relationships between sociodemographic variables, intolerance to uncertainty (INT), social support, and psychological distress (i.e., indicators of Common Mental Disorders (CMDs) and perceived stress (PS)) in Brazilian men during the COVID-19 pandemic. Methods: A cross-sectional study with national coverage, of the web survey type, and conducted with 1006 Brazilian men during the period of social circulation restriction imposed by the health authorities in Brazil for suppression of the coronavirus and control of the pandemic. Structural equation modeling analysis was performed. Results: Statistically significant direct effects of race/skin color $(\lambda=0.268$; $p$-value $<0.001)$, socioeconomic status (SES) $(\lambda=0.306 ; p$-value $<0.001)$, household composition
\end{abstract}


$(\lambda=0.281 ; p$-value $<0.001)$, PS $(\lambda=0.513 ; p$-value $<0.001)$, and INT $(\lambda=0.421 ; p$-value $<0.001)$ were evidenced in the occurrence of CMDs. Black-skinned men with higher SES, living alone, and with higher PS and INT levels presented higher prevalence values of CMDs. Conclusions: High levels of PS and INT were the factors that presented the strongest associations with the occurrence of CMDs among the men. It is necessary to implement actions to reduce the stress-generating sources as well as to promote an increase in resilience and the development of intrinsic reinforcements to deal with uncertain threats.

Keywords: men's health; COVID-19; mental disorders; stress; psychological; social support

\section{Introduction}

The health crisis caused by COVID-19 exerted a negative impact on the mental health of the world's population. The experience of unknown situations and the fear of contamination imposed by the burden of the disease and its repercussions produced new daily stressors and exacerbated previous ones already structurally present in societies [1-4]. Together, these factors generate continuous situations of suffering and contribute to the increase in psychological distress, as evidenced by indicators of Common Mental Disorders (CMDs) and perceived stress [5-7]. While the former refer to a set of symptoms, such as fatigue, insomnia, irritability, problems concentrating, and somatizations [5-8], the latter involves feelings about the uncontrollable and unpredictable nature of everyday events and the individual assessment of the ability to face such questions $[4,5]$.

It is estimated that nearly one billion people are affected by some mental disorder due to the pandemic, with an emphasis on symptoms of anxiety, anguish and depression, and disorders resulting from alcohol use and substance abuse in addition to the increase in suicide rates [1-6]. The deleterious effects caused by the pandemic have been measured and show a reduction in life expectancy at birth, in the ability to work, and in absenteeism and presentism in addition to growth in unemployment and informality. Jointly, these situations install contexts that culminate in massive mental ailments in the male population [9-13].

The rapid spread of COVID-19, associated with the need for social distancing, forced quarantine, and blockades across the world, has placed imposed high stress levels on people $[14,15]$, and sustaining these measures has increased the prevalence of CMDs in the populations [16,17], contributing to the increase in depressive and anxiety disorders, identified by the WHO as the most common psychiatric diseases in the world's population $[18,19]$. Studies carried out prior to the COVID-19 pandemic identified high prevalences of CMD in men in Brazil, which ranged from 11.1\% [20,21].

Consequently, the COVID-19 pandemic resulted in a psychologically chaotic and dismal setting. The radical changes in the individuals' daily routines and the general context of fear and insecurity converge to unfamiliar situations and significant uncertainties that, due to their persistence over time, also provoke reactions of intolerance to this uncertainty $[5,7]$. Intolerance to uncertainty is described as the predisposition of an individual to consider the possibility of a negative event occurring regardless of the possibility of its actual occurrence as unacceptable $[1,2]$.

Thus, intolerance to uncertainty is considered as one of the main underlying components of anxiety disorders [22], obsessive compulsive disorder (OCD) [23], post-traumatic stress disorder in depression [24], depression [25], and panic disorder [26]. Thus, inability to cope with uncertainty can be a negative predictor for well-being [27].

Social support is a basic human need and an important moderator of the impacts of the high psychological demands related to the COVID-19 pandemic. High social support has a protective effect and mitigates the negative impacts of stress on physical and psychological well-being [28]. Thus, the social support received during the pandemic is able to provide positive reinforcement to deal with stressful situations and prevent the occurrence/worsening of CMD. 
In addition, there is evidence that CMDs are associated with social inequalities, as individuals in unfavorable socioeconomic conditions (e.g., black individuals, low income, and low level of education) are in a situation of greater vulnerability due to the constant experience of the feeling of insecurity, hopelessness, and risk of violence [29-31]. These sensations were possibly exacerbated by the COVID-19 pandemic, which supports the need to verify this association in men in Brazil, a country known to be marked by social inequalities and inequities.

Similarly, higher prevalence of CMD has been observed in people who live alone [32]. Overall, the loneliness of living alone largely explains the association with CMD [32]. Due to the need for social isolation to prevent and control COVID-19, people who live alone are even more susceptible to loneliness, which represents an increase in the potential risk for the development of CMD.

Epidemiological indicators, such as the number of new cases, the rates and length of hospital stay, the unfavorable outcomes of the disease, and the number of deaths have shown that the male population has been more impacted, evidencing that being a man is a risk factor for COVID-19 [33,34]. However, these results are restricted to the physical dimension of the disease and hardly advance the analysis of the mental health dimension $[35,36]$.

In addition to that, population-based studies investigating the mental health situation in the context of the pandemic have included predominantly female samples [37-39], which limits a more comprehensive identification of the magnitude of the problem and, consequently, restricts the adoption of coping measures to a specific audience. In this context, this study contributes to overcoming this gap in scientific knowledge based on the research and appreciation of aspects related to the male population, which permeate the subjectivities and the social, symbolic, psychological, and psycho-emotional constructions of the population and their repercussions on health $[40,41]$.

Given the above, it is considered crucial to give visibility to the mental health of male populations and to the aspects associated with the occurrence of mental disorders to strengthen the confrontation of the life dimensions affected by the pandemic in addition to contributing to overcoming this moment of profound health and social crisis generated by the dissemination of COVID-19.

Thus, this study aimed at analyzing the relationships between sociodemographic variables, intolerance to uncertainty (INT), social support, and psychological distress, that is, indicators of Common Mental Disorders (CMDs) and perceived stress (PS), in Brazilian men during the COVID-19 pandemic.

\section{Methods}

\subsection{Type of Study}

A cross-sectional study with national coverage, of the web survey type, and carried out during the period of social circulation restriction imposed by the health authorities in Brazil for suppression of the coronavirus and control of the pandemic.

\subsection{Sample and Participants}

The sample was estimated at 923 participants, considering the population of 64,520,660 Brazilian men with Internet access [42], 50\% prevalence estimate, 95\% confidence level, $5 \%$ precision, $80 \%$ power, effect of study design of two, and a $20 \%$ increase for losses.

The snowball technique [43] was used to recruit the participants through digital social networks (Facebook ${ }^{\circledR}$, Instagram ${ }^{\circledR}$, WhatsApp ${ }^{\circledR}$, Grindr $^{\circledR}$ ). This is a non-probabilistic sampling technique performed by means of reference chains, where the first eligible and recruited participants invite new participants from their network of contacts (family, friends and acquaintances) who, in turn, indicate new participants and so on successively, until the estimated sample is minimally reached.

Initially, 25 participants were recruited, five from each of the Brazilian regions, who were called seeds. These participants were encouraged to send the research link to other 
men from their contact networks. At the end, 27 seeds were recorded, one from each of the Brazilian states.

The inclusion criteria adopted were as follows: being digitally literate to access the Internet and being at least 18 years old. The individuals excluded were those non-residents, in Brazil, or who were in the country at the time of data collection.

\subsection{Procedures, Measurements, Variables and Outcome}

For data collection, a questionnaire that was structured in blocks was used, including the following:

(a) Sociodemographic characteristics: sexual identity, age, schooling, self-reported race/skin color, house-sharing or not, work situation, and use of health plans;

(b) Common Mental Disorders (CMDs): the Self-Reporting Questionnaire (SRQ-20) was used to screen CMDs. SRQ-20 is validated for use in Brazil with satisfactory performance indicators [44-46]. It consists of 20 items with dichotomous answer categories (0-no; $1-$ yes). The cutoff point for men is at least five positive answers [47];

(c) Perceived Stress level: the ten-item version of the Perceived Stress Scale (PSS10) [47], cross-culturally adapted [48] and validated for use in the Brazilian population [49], was used. The items have five-point Likert-type answer options $(0=$ never, $1=$ almost never, 2 = sometimes, 3 = almost always, 4 = always) and are distinguished in questions with positive and negative connotations, thus inverting the score of the positive questions. The perceived stress score is calculated by the sum of the scores obtained in the ten items $[47,48]$. The levels were categorized as low (from zero to 13 points), moderate (from 14 to 26 points), and high (27 points or more) [50];

(d) Level of intolerance to uncertainty: the Intolerance of Uncertainty Scale (IUS) [51], 12-item version (IUS-12) [52], cross-culturally adapted [53] and validated for use in the Brazilian population [54], was applied. The items contain answer options arranged in a Likert scale, varying from one (not at all characteristics) to five (very characteristic) and assessing two dimensions: prospective IU (seven items) and inhibitory IU (five items). The validation study in Brazil evidenced a two-factor structure with high correlation between them (0.83) [55], which can indicate the existence of a higher-order factor (intolerance to uncertainty) [24,56]. The literature published to the present day indicates diverse evidence of the one-factor solution of intolerance to uncertainty as well as the use of its overall score $[57,58]$. The higher the score, the greater the level of intolerance to uncertainty. The IUS-12 latent construct showed adequate internal consistency $(\alpha=0.89 ; \omega=0.89)$;

(e) Level of social support: the instrument used was the 2-Way Social Support Scale (2-WSSS) [58], 20-item version, transculturally adapted and validated in Brazil [59]. 2-WSSS assesses four social support dimensions: (1) receiving emotional support (seven items); (2) receiving instrumental support (four items); (3) offering emotional support (four items); and (4) offering instrumental support (five items). The items are answered in a Likert scale, varying from zero (it never applies) to five (it always applies). Higher scores indicate higher levels of social support. In this study, 2-WSSS presented satisfactory internal consistency $(\alpha=0.85 ; \omega=0.96)$.

The self-reporting questionnaire was elaborated in a specific data-collection platform and made available through the Internet. From then onwards, it was widely publicized on Facebook ${ }^{\circledR}$, Instagram ${ }^{\circledR}$, WhatsApp ${ }^{\circledR}$, and Grindr ${ }^{\circledR}$ digital social networks by five trained researchers for autonomous and voluntary adherence as well as by making a direct invitation to the individuals who met the eligibility criteria. The data were collected between May and September 2020. The participants had access to the questionnaire after reading and signing the free and informed consent form and thus agreeing to participate in the study. Before each block of questions, the necessary information to answer them were made available as well as the option not to answer any question. The instructions about the recall period for each instrument were clarified. 


\subsection{Conceptual Framework and Study Hypotheses}

Considering the evidence found in the literature, the understanding of human behaviors related to coping with the coronavirus outbreak and its impacts on people's mental health, Directed Acyclic Graphs (DAGs) were constructed [60,61] to represent the conceptual structure of the common mental disorders in Brazilian men during the COVID-19 pandemic, with emphasis on the effect of race/skin color, house-sharing or not, social support, perceived stress, and intolerance to uncertainty. The directly observed variables are represented by rectangles and the latent variables by circles (Figure 1).

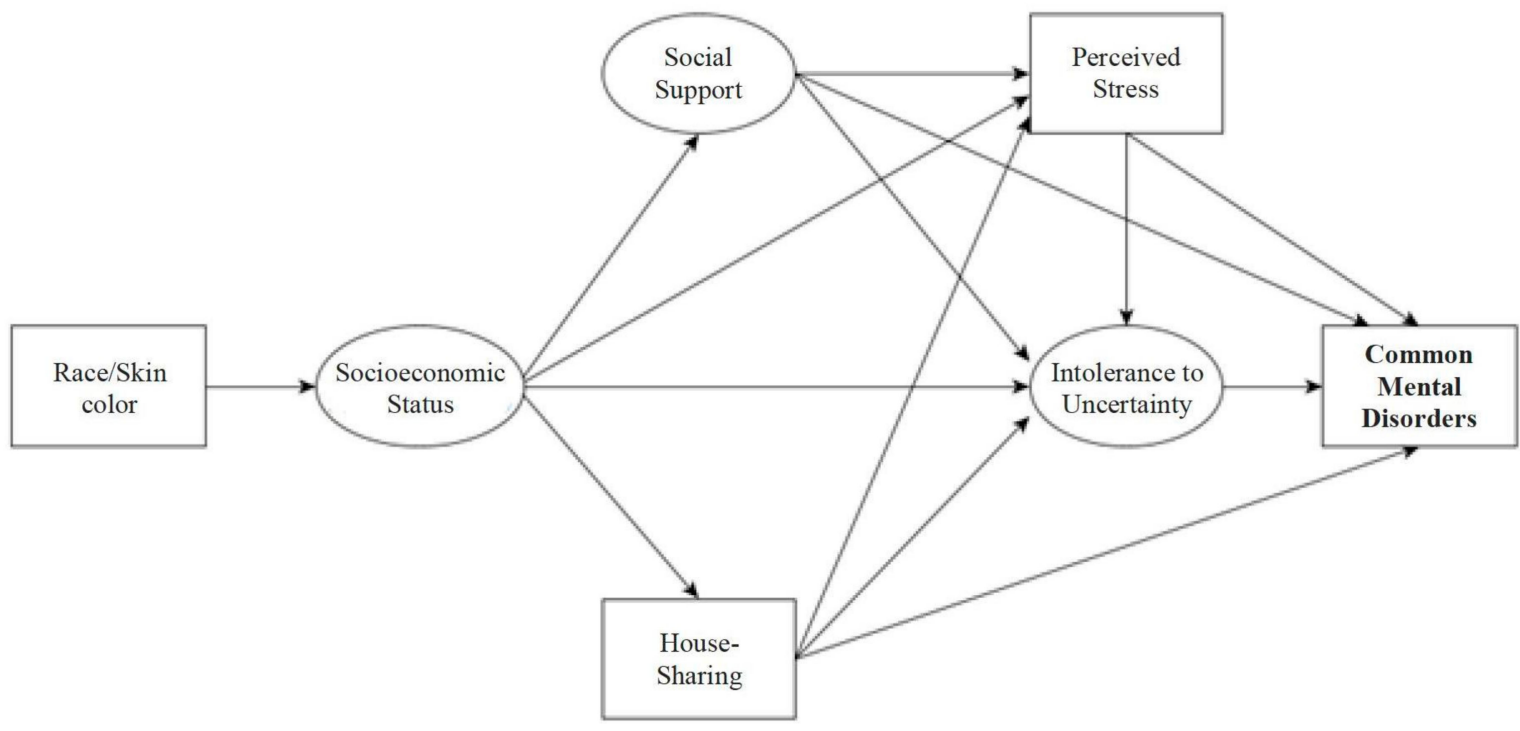

Figure 1. Conceptual structure of the determinants for the occurrence of CMDs in Brazilian men during the COVID-19 pandemic.

DAGs are diagrams that allow coding and explaining conceptual hypotheses [61], with growing recognition in the field of causal research in epidemiology $[60,62,63]$. In the DAGs, the relationships between events are represented by vertices connected by edges; the vertices represent the variables, and the edges show the possible ways or paths of relationships between variables, explaining causal links [61]. These causal paths can indicate direct causes if there is an arrow going from one variable to another or indirect causes if there is a sequence of arrows starting from one variable and reaching another, passing through one or more intermediate/mediating variables. Paths that do not follow the direction of the arrows linking exposure and outcome represent potential "confounding paths" [60].

\subsection{Statistical Analysis}

For the statistical analysis, the data were transferred from the Google Forms platform to a Microsoft Excel spreadsheet and were later organized in the SPSS software, version 24.0. Initially, a descriptive analysis of the variables of interest was performed for an estimation of frequencies (absolute and relative) and of prevalence values for CMDs. Pearson's chisquare test was used, with a significance level of $5 \%$, to verify the association between CMDs (outcome) and the independent variables. Subsequently, the database was exported to the Mplus software, version 8.0, for Structural Equation Modeling (SEM) analyses.

To perform the SEM, the latent constructs were measured (measuring models) [64]. To assess the factor structure of the observable items, Exploratory Factor Analysis (EFA) was performed, followed by Exploratory Structural Equation Models (ESEM) and Confirmatory Factor Analysis (CFA) to validate dimensionality of the construct elaborated [65], having as criteria a standardized factor load $\geq 0.3$ and a residual variance $\leq 0.7[66,67]$.

To evaluate the structural model constituted by the observed and latent variables, unadjusted and standardized regression coefficients were estimated, with $95 \%$ confidence 
intervals $(95 \% \mathrm{CI})$ and $p$-value $<0.05$. The size of the direct, indirect, and total effects were classified as follows: weak/small (around 0.10), moderate/medium (close to 0.30), and strong/big (>0.50) [68].

The Weighted Least-Squares Means and Variance Adjusted (WLSMV) estimator was used as a function of the modeling with categorical data. To re-specify the model, the Modification Indices ( $\mathrm{MI} \geq 10$ ) and the Expected Parameter Changes (EPC $\geq 0.25)$ were assessed [69]. To assess fit of the models, the Root Mean-Square Error of Approximation (RMSEA > 0.06-exceptionally < 0.08, with a 90\% confidence interval below 0.08) [69], the Comparative Fit Index (CFI $\geq 0.95)$, and the Tucker-Lewis Index (TLI $\geq 0.95)$ were adopted [68].

\subsection{Ethical Considerations}

Ethical approval regarding this study was obtained from the institutional ethics committee (decision: 4,087,611; CAAE: 32889420.9.0000.5531). All the participants in this study were only included after informed consent had been obtained from them. All procedures performed in this study were compatible with the ethical standards of the institutional research committee and with those of the Declaration of Helsinki and its comparable ethical standards.

\section{Results}

The study participants were 1006 men. The predominant profile included nonheterosexuals $(54.1 \%)$, aged from 29 to 39 years old $(45.1 \%)$, higher education $(73.8 \%)$, black-skinned individuals $(59.2 \%)$, without a partner $(67.3 \%)$, with monthly income up to two minimum wages (41.6\%), living with family members / friends $(76.6 \%)$, and workers (75.0\%). A high proportion of people depending exclusively on SUS care and services was observed (41.9\%) (Table 1$)$.

Table 1. Sociodemographic and occupational characteristics and prevalence of CMD in Brazilian men during the COVID-19 pandemic. Brazil, 2020. ( $\mathrm{N}=1.006)$.

\begin{tabular}{|c|c|c|c|c|c|}
\hline Variables & $N$ & $\%$ & $\mathbf{N}$ & $p$ & $p$-Value \\
\hline \multicolumn{6}{|l|}{ Sexual identity $(\mathrm{N}=945)$} \\
\hline Heterosexual & 434 & 45.9 & 228 & 52.5 & 0.785 \\
\hline Non-heterosexual & 511 & 54.1 & 273 & 53.4 & \\
\hline \multicolumn{6}{|l|}{ Age group } \\
\hline 18 to 28 years old & 314 & 31.2 & 197 & 62.7 & $<0.001$ \\
\hline 29 years old to 39 years old & 454 & 45.1 & 257 & 56.6 & \\
\hline 40 years or more & 238 & 23.7 & 92 & 38.7 & \\
\hline \multicolumn{6}{|l|}{ Education } \\
\hline Elementary/high school & 264 & 26.2 & 146 & 55.3 & 0.696 \\
\hline University education & 742 & 73.8 & 400 & 53.9 & \\
\hline \multicolumn{6}{|l|}{ Race/color $(\mathrm{N}=1.001)$} \\
\hline White & 376 & 37.4 & 197 & 52.4 & 0.247 \\
\hline Yellow & 19 & 1.9 & 11 & 57.9 & \\
\hline Brown & 397 & 39.5 & 211 & 53.1 & \\
\hline Black & 196 & 19.5 & 116 & 59.2 & \\
\hline Indigenous & 13 & 1.3 & 10 & 76.9 & \\
\hline \multicolumn{6}{|l|}{ Marital status } \\
\hline With partner & 329 & 32.7 & 152 & 46.2 & $<0.001$ \\
\hline No partner & 677 & 67.3 & 394 & 58.2 & \\
\hline \multicolumn{6}{|l|}{ Monthly income * } \\
\hline Up to 2 salaries & 418 & 41.6 & 203 & 56.4 & 0.083 \\
\hline 3 to 4 salaries & 228 & 22.7 & 109 & 47.8 & \\
\hline 5 salaries or more & 360 & 35.8 & 234 & 56.0 & \\
\hline Who they reside with $(\mathrm{N}=1.005)$ & & & & & \\
\hline
\end{tabular}


Table 1. Cont.

\begin{tabular}{|c|c|c|c|c|c|}
\hline Variables & $N$ & $\%$ & $\mathbf{N}$ & $p$ & $p$-Value \\
\hline Family/Friend(s) & 770 & 76.6 & 409 & 53.1 & 0.163 \\
\hline Alone & 235 & 23.4 & 137 & 59.3 & \\
\hline \multicolumn{6}{|l|}{ Work situation } \\
\hline It works & 755 & 75.0 & 397 & 52.6 & 0.062 \\
\hline Does not work & 251 & 25.0 & 149 & 59.4 & \\
\hline \multicolumn{6}{|l|}{ Use of health plan } \\
\hline Exclusively SUS & 376 & 37.4 & 207 & 55.1 & 0.040 \\
\hline SUS and private plan & 369 & 36.7 & 214 & 58.0 & \\
\hline Exclusively private plan & 261 & 25.9 & 125 & 47.9 & \\
\hline \multicolumn{6}{|l|}{ Perceived stress } \\
\hline Low & 223 & 22.2 & 26 & 11.7 & $<0.001$ \\
\hline Moderate & 613 & 60.9 & 363 & 59.2 & \\
\hline High & 170 & 16.9 & 157 & 92.4 & \\
\hline \multicolumn{6}{|l|}{ Uncertainty intolerance } \\
\hline Low & 327 & 32.5 & 79 & 24.2 & $<0.001$ \\
\hline Moderate & 317 & 31.5 & 169 & 53.3 & \\
\hline High & 362 & 36.0 & 298 & 82.3 & \\
\hline \multicolumn{6}{|l|}{ Receive social support } \\
\hline High & 371 & 36.9 & 160 & 43.1 & $<0.001$ \\
\hline Moderate & 309 & 30.7 & 167 & 54.0 & \\
\hline Low & 326 & 32.4 & 219 & 67.2 & \\
\hline \multicolumn{6}{|l|}{ Give social support } \\
\hline Low & 334 & 33.2 & 186 & 55.7 & 0.765 \\
\hline Moderate & 275 & 27.3 & 145 & 52.7 & \\
\hline High & 397 & 39.5 & 215 & 54.2 & \\
\hline
\end{tabular}

p, prevalence; SUS, public health system. * Minimum wage in force in the period of data collection: $\mathrm{R} \$ 1045,00$.

The overall prevalence of CMDs was 54.3\%. Higher prevalence of CMDs was observed among the youngest individuals (62.7\%), those with lower schooling (55.3\%), black-skinned $(55.1 \%)$, without a partner $(58.2 \%)$, and among those who lived alone $(58.3 \%)$, did not work $(59.4 \%)$, had high levels of stress $(92.4 \%)$, intolerance to uncertainty $(82.3 \%)$, and received low social support (67.2\%). The moderate stress levels reached $60.9 \%$, while $36.0 \%$ reported high levels of intolerance to uncertainty. Receiving high social support was mentioned by $36.9 \%$ and offering high social support by $39.5 \%$ (Table 1 ).

Socioeconomic status (SES), intolerance to uncertainty (INT), and social support (SS) were treated as latent constructs. In general, the factor loads of the measuring models were high and statistically significant. The factor loads of the SES latent construct were above 0.60 . In this construct, the highest load was observed for the occupational situation (OCP) indicator $(\lambda=0.690)$, and the lowest was found in the use of health plan (HP) indicator $(\lambda=0.609)$ (Table 2).

Table 2. Standardized factor loads of the measuring models of socioeconomic status, intolerance to uncertainty and social support among Brazilian men in the COVID-19 pandemic context. Brazil, 2020.

\begin{tabular}{cccc}
\hline Latent Variables & Indicating Variables (Codes) & SFL $^{\text {a }}$ & \\
\hline SES & Schooling (SCH) & 0.631 & $<0.001$ \\
& Occupational situation (OCP) & 0.690 & $<0.001$ \\
Monthly income (INC) & 0.664 & $<0.001$ & $<0.001$ \\
\hline
\end{tabular}


Table 2. Cont.

\begin{tabular}{|c|c|c|}
\hline Indicating Variables (Codes) & SFL $^{\mathrm{a}}$ & $p$-Value \\
\hline \multicolumn{3}{|l|}{ INT } \\
\hline Uncertainty prevents me from living a full life (I1) & 0.747 & $<0.001$ \\
\hline I profoundly loathe unforeseen events (I2) & 0.710 & $<0.001$ \\
\hline I feel frustrated when I don't have all the information I need (I3) & 0.669 & $<0.001$ \\
\hline It is necessary to think about the future to avoid surprises (I4) & 0.393 & $<0.001$ \\
\hline A small unforeseen event can ruin everything, even with the best planning (I5) & 0.749 & $<0.001$ \\
\hline When it's time to act, uncertainty paralyzes me (I6) & 0.620 & $<0.001$ \\
\hline Uncertainty makes me vulnerable (I7) & 0.754 & $<0.001$ \\
\hline I always want to know what the future will bring me (I8) & 0.611 & $<0.001$ \\
\hline I hate to be taken by surprise (I9) & 0.610 & $<0.001$ \\
\hline The slightest sign of doubt dissuades me from acting (I10) & 0.678 & $<0.001$ \\
\hline I should be able to organize everything beforehand (I11) & 0.634 & $<0.001$ \\
\hline Uncertainty does not allow me to sleep well (I12) & 0.694 & $<0.001$ \\
\hline \multicolumn{3}{|l|}{ Receiving } \\
\hline I have someone I can talk to about the pressures in my life (S1) & 0.838 & $<0.001$ \\
\hline There is at least one person with whom I can share most of the things (S2) & 0.838 & $<0.001$ \\
\hline When I'm feeling down, there's someone I can count on (S3) & 0.907 & $<0.001$ \\
\hline I have someone in my life who offers me emotional support (S4) & 0.899 & $<0.001$ \\
\hline There is at least one person in whom I feel I can trust (S5) & 0.820 & $<0.001$ \\
\hline There is someone in my life who makes me feel that I'm worthy (S6) & 0.689 & $<0.001$ \\
\hline I feel that I have a network of people who value me (S7) & 0.609 & $<0.001$ \\
\hline \multicolumn{3}{|l|}{ RIS } \\
\hline If I'm in trouble, someone will help me (S13) & 0.845 & $<0.001$ \\
\hline I have someone to help me when I'm ill (S14) & 0.686 & $<0.001$ \\
\hline If I need money, I know someone who can help me (S15) & 0.649 & $<0.001$ \\
\hline There is someone who can help me fulfill my responsibilities (S16) & 0.594 & $<0.001$ \\
\hline \multicolumn{3}{|l|}{ OIS } \\
\hline I'm a person who is available to listen to others' problems (S8) & 0.697 & $<0.001$ \\
\hline I seek to encourage people when they're feeling down (S9) & 0.723 & $<0.001$ \\
\hline People close to me tell me their deepest concerns (S10) & 0.710 & $<0.001$ \\
\hline I comfort other people in difficult times (S11) & 0.867 & $<0.001$ \\
\hline People trust me when they have problems (S12) & 0.737 & $<0.001$ \\
\hline \multicolumn{3}{|l|}{ OES } \\
\hline I help others when they are too busy (S17) & 0.685 & $<0.001$ \\
\hline I helped someone with their responsibilities when they were not able to fulfill them (S18) & 0.700 & $<0.001$ \\
\hline I provided help when someone who lived with me was ill (S19) & 0.588 & $<0.001$ \\
\hline I'm a person whom others ask for help with tasks (S20) & 0.401 & $<0.001$ \\
\hline \multicolumn{3}{|l|}{$\mathrm{RS}^{\mathrm{a}}$} \\
\hline RES b & 0.882 & $<0.001$ \\
\hline RIS $^{b}$ & 0.949 & $<0.001$ \\
\hline \multicolumn{3}{|l|}{ Offering } \\
\hline OIS $^{b}$ & 0.857 & $<0.001$ \\
\hline $\mathrm{OES}^{\mathrm{b}}$ & 0.740 & $<0.001$ \\
\hline
\end{tabular}

SFL, standardized factor loads; SES, socioeconomic status; INT, intolerance to uncertainty; RES, receiving emotional support; RIS, receiving instrumental support; OIS, offering instrumental support; OES, offering emotional support; RS, receiving support; OS, offering support. ${ }^{a}$ 2nd-order factor; ${ }^{b} 1$ st-order factor.

As for the INT construct, the exploratory factor analysis revealed, based on the eigenvalues, a solution of one predominant factor (eigenvalues $=5.907$ ) with a marked reduction for two factors (eigenvalue = 1283). In the ESEM, the correlation between prospective and inhibitory IU was 0.992 , and only the one-factor solution presented satisfactory fit indices. For this one-factor model, the highest load was observed for the "uncertainty makes me 
vulnerable" item (I7) $(\lambda=0.754)$ and the lowest one for "it is necessary to think about the future to avoid surprises" (I4) $(\lambda=0.393)$ (Table 2).

The SS measuring model was initially evaluated by the indicators of the first-order factors: receiving emotional support (RES), receiving instrumental support (RIS), offering emotional support (OES), and offering instrumental support (OIS), all with high factor loads and statistically significant. For RES and RIS, the highest loads were observed for the items "when I'm feeling down, there's someone I can count on" (S3) $(\lambda=0.907)$ and "if I'm in trouble someone will help me" (S13) $(\lambda=0.845)$ and the lowest ones for "I feel I have a network of people who value me" (S7) $(\lambda=0.609)$ and "there's someone who can help me fulfill my responsibilities" (S16) $(\lambda=0.594)$, respectively. For GES and GIS, greater burdens were verified for "I helped someone with their responsibilities when they were not able to fulfill them" (S18) $(\lambda=0.700)$ and "I comfort other people in difficult times" (S11) $(\lambda=0.867)$ and lower ones for "I'm a person whom others ask for help with tasks" (S20) $(\lambda=0.401)$ and "I'm a person available to listen to others' problems" (S8) $(\lambda=0.697)$, respectively. The high correlation between the constructs of receiving $(\mathrm{r}=0.832)$ and offering $(\mathrm{r}=0.864)$ support endorsed the existence of the respective second-order factors called receiving support (RS) and offering support (OS), without a significant residual correlation $(\mathrm{r}=0.430)$ (Table 2).

The SES, INT, and SS measuring models obtained satisfactory fit indices. The evaluation of the correlations between these latent constructs, both between the second-order factors of the SS model and in the model considering the correlations between all the latent variables, evidenced adequate discriminant validity $(r<0.90)$ (Table 3$)$.

Table 3. Fit indicators of the measuring models, using CMDs as response variable, Brazil, 2020.

\begin{tabular}{|c|c|c|c|c|}
\hline Indices & SES & INT & SS (RS $\square$ OS) & CMM \\
\hline \multicolumn{5}{|l|}{ RMSEA } \\
\hline Index & 0.038 & 0.049 & 0.046 & 0.046 \\
\hline $90 \%$ CI & $0.000-0.078$ & $0.040-0.059$ & $0.041-0.050$ & $0.043-0.048$ \\
\hline$p$-Value & 0.671 & 0.518 & 0.939 & 0.998 \\
\hline CFI & 0.997 & 0.992 & 0.959 & 0.976 \\
\hline TLI & 0.991 & 0.986 & 0.950 & 0.974 \\
\hline \multicolumn{5}{|l|}{$\mathrm{R}^{\mathrm{a}}$} \\
\hline RSTOS & - & - & 0.430 & - \\
\hline SES INT & - & - & - & -0.098 \\
\hline SESTRS & - & - & - & -0.019 \\
\hline SESTOS & - & - & - & -0.033 \\
\hline INT QRS & - & - & - & -0.325 \\
\hline INT OS & - & - & - & -0.067 \\
\hline
\end{tabular}

SES, socioeconomic status; INT, intolerance to uncertainty; SS, social support; RS, receiving social support; OS, offering social support; CMM, Correlated Measuring Models; RMSEA, Root Mean Square Error of Approximation; 90\% CI, 90\% confidence interval; TLI, Tucker-Lewis Index; CFI, Comparative Fit Index. ${ }^{\text {a }}$ Residual correlations (1) between the latent variables.

In the structural model, CMDs was considered as response variable. The SES, RS, OS, and INT latent variables and the self-reported race/color (COL), house-sharing (HS), and perceived stress (PS) observed variables were used as explanatory variables. The direct effects for CMDs were assessed for all the variables of the model, with the exception of OS, and their structural inter-relationships were considered in the paths of specific indirect effects. The estimated structural equation model presented adequate fit indices (Figure 2).

Statistically significant direct effects were evidenced with COL $(\lambda=-0.268$; $p$-value $<0.001)$, SES $(\lambda=0.306 ; p$-value $<0.001)$, HS $(\lambda=0.281 ; p$-value $<0.001)$, PS $(\lambda=0.513 ; p$-value $<0.001)$, and INT $(\lambda=0.421 ; p$-value $<0.001)$ for the CMDs. Thus, black-skinned men, those with higher socioeconomic status, living alone, and with higher levels of stress and intolerance to uncertainty presented higher prevalence values of CMDs. There were strong effects of PS and INT and medium effects of the other variables, showing that high levels of stress and intolerance to uncertainty were the factors with the strongest direct associations with the prevalence of CMDs (Figure 2). 


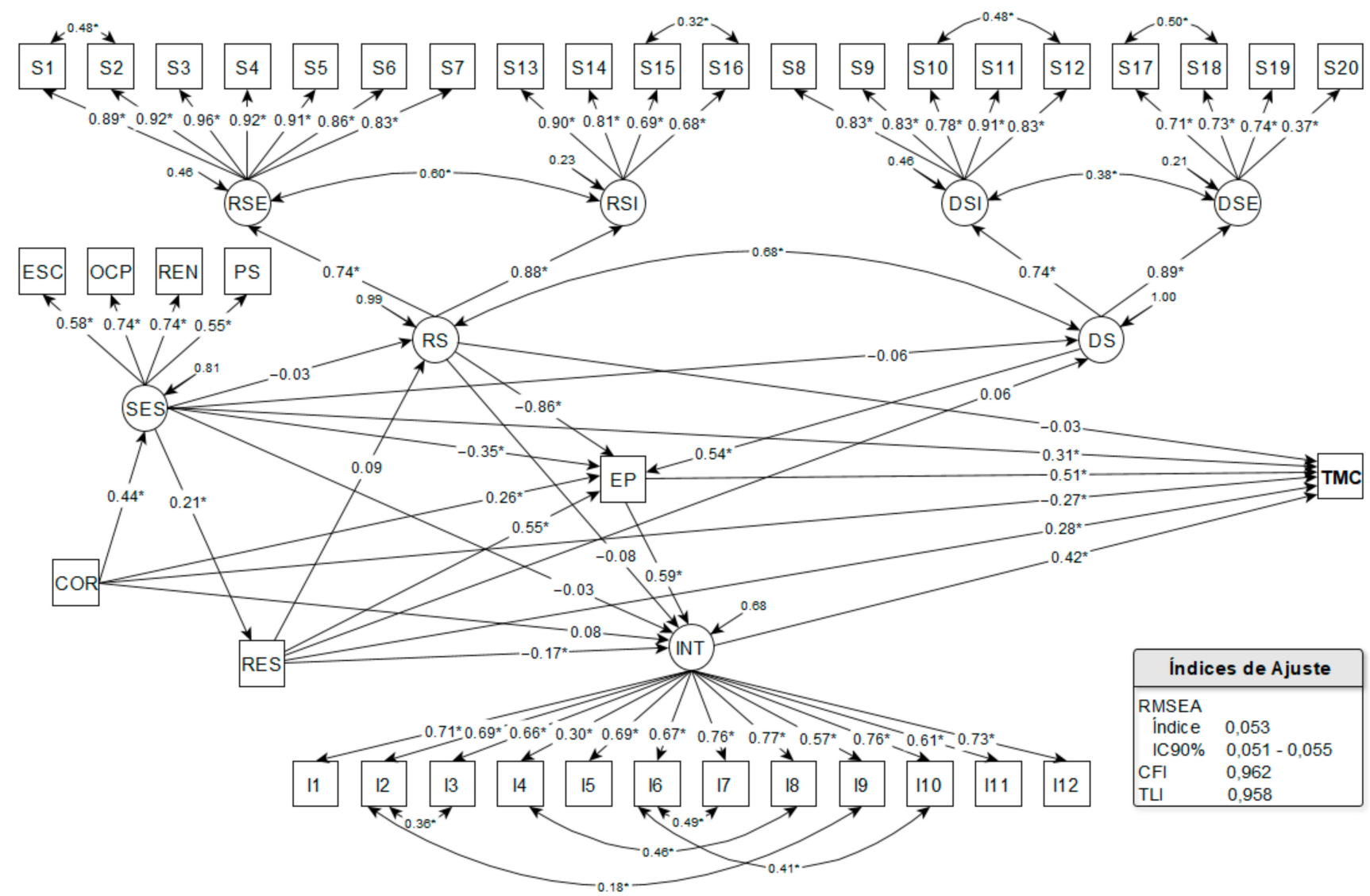

Figure 2. Structural equation model with direct and indirect specific effects for CMDs among Brazilian men in the COVID-19 pandemic context. Brazil, 2020. SES, socioeconomic status; INT, intolerance to uncertainty (I1-I12: indicating variables); RES, receiving emotional support (S1-S7: indicating variables); RIS, receiving instrumental support (S13-S16: indicating variables); OIS, offering instrumental support (S8-S12: indicating variables); OES, offering emotional support (S17-S20: indicating variables); RS, receiving support; OS, offering support; $\mathrm{SCH}$, schooling; $\mathrm{OCP}$, occupational status; INC, monthly income; HP, use of health plan; COL, race/skin color; HS, house-sharing; PS, perceived stress; I1-I12, items 1 to 12; S1-S20, items 1 to 20; RMSEA, Root Mean Square Error of Approximation; 90\%CI, 90\% confidence interval; CFI, Comparative Fit Index; TLI, Tucker-Lewis Index. * Statistically significant loads ( $p$-value $<0.05)$.

The analysis of the specific indirect paths enabled the identification of important mediators of the effect of the explanatory variables on CMDs. Socioeconomic status was an important mediator of the relationship between race/skin color and CMDs, pointing out that non-black-skinned men with higher socioeconomic status presented a higher prevalence of CMDs. The effect of race/skin color and socioeconomic status was strong and significant $(\lambda=0.441 ; p$-value $<0.001)$ (Figure 2$)$.

The level of perceived stress was also a mediator in the association chain between SES and social support with CMDs. It was evidenced that men with lower socioeconomic status $(\lambda=0.349 ; p$-value $<0.001)$, non-black-skinned $(\lambda=0.263 ; p$-value $<0.001)$, who lived alone $(\lambda=0.547 ; p$-value $<0.001)$, received low social support $(\lambda=0.860 ; p$-value $<0.001)$, and offered high social support $(\lambda=0.536$; $p$-value $<0.001)$ had higher stress levels; and higher stress level was associated with a higher prevalence of CMDs. The factors that most contributed (strong effects) to the increase in the level of perceived stress were the following: receiving low social support, living alone, and offering high social support (Figure 2).

Living alone mediated the effect of SES on CMDs, evidencing that men with higher socioeconomic status had higher stress levels and more prevalence of CMDs. The level 
of intolerance to uncertainty was also an important effect mediator: men who lived with family members $/$ friends $(\lambda=0.170 ; p$-value $=0.021)$, notably non-black-skinned and those with higher socioeconomic status, had a higher level of intolerance to uncertainty and higher prevalence of CMDs. Intolerance to uncertainty also mediated the effect of perceived stress on CMDs, indicating that men with higher stress levels, especially those with lower socioeconomic status, non-black-skinned, who lived alone and with low levels of receiving social support, and high levels of offering social support, had higher levels of intolerance to uncertainty $(\lambda=0.592 ; p$-value $<0.001)$, resulting in a higher prevalence of CMDs. The factor that most contributed to the increase in intolerance to uncertainty was the high level of perceived stress, with a strong and significant effect (Figure 2).

The greatest total effects in CMDs were observed for higher level of perceived stress $(\lambda=0.763 ; p$-value $<0.001)$, receiving low social support $(\lambda=0.716 ; p$-value $<0.001)$, living alone $(\lambda=0.587 ; p$-value $<0.001)$, high intolerance to uncertainty $(\lambda=0.421 ; p$-value $<0.001)$, and high social support $(\lambda=0.409 ; p$-value $<0.001)$, all strong and significant. There was a small overall effect of socioeconomic status $(\lambda=0.183 ; p$-value $<0.001)$, but the indirect effects, mediated by high levels of perceived stress and intolerance to uncertainty, were robust and significant (Table 4 ).

Table 4. Standardized total and indirect effects of the structural equation model, using CMDs as response variable among Brazilian men in the COVID-19 pandemic context. Brazil, 2020.

\begin{tabular}{|c|c|c|c|c|}
\hline Paths & SFL & SE & Est/SE ${ }^{a}$ & $p$-Value ${ }^{b}$ \\
\hline \multicolumn{5}{|l|}{ Total Effects } \\
\hline $\mathrm{INT} \rightarrow \mathrm{CMDs}$ & 0.421 & 0.047 & 8.87 & $<0.001$ \\
\hline $\mathrm{RS} \rightarrow \mathrm{CMDs}$ & -0.716 & 0.051 & -14.12 & $<0.001$ \\
\hline $\mathrm{OS} \rightarrow \mathrm{CMDs}$ & 0.409 & 0.021 & 19.11 & $<0.001$ \\
\hline $\mathrm{SES} \rightarrow \mathrm{CMDs}$ & 0.183 & 0.043 & 4.21 & $<0.001$ \\
\hline $\mathrm{PS} \rightarrow \mathrm{CMDs}$ & 0.763 & 0.039 & 19.46 & $<0.001$ \\
\hline $\mathrm{COL} \rightarrow \mathrm{CMDs}$ & -0.021 & 0.040 & -0.53 & 0.595 \\
\hline $\mathrm{HS} \rightarrow \mathrm{CMDs}$ & 0.587 & 0.035 & 16.75 & $<0.001$ \\
\hline \multicolumn{5}{|l|}{ Specific indirect effects } \\
\hline \multicolumn{5}{|l|}{ RS } \\
\hline $\mathrm{RS} \rightarrow \mathrm{PS} \rightarrow \mathrm{CMDs}$ & -0.442 & 0.039 & -11.46 & $<0.001$ \\
\hline $\mathrm{RS} \rightarrow \mathrm{INT} \rightarrow \mathrm{CMDs}$ & -0.032 & 0.025 & -1.31 & 0.190 \\
\hline $\mathrm{RS} \rightarrow \mathrm{PS} \rightarrow \mathrm{INT} \rightarrow \mathrm{CMDs}$ & -0.214 & 0.037 & -5.84 & $<0.001$ \\
\hline \multicolumn{5}{|l|}{ OS } \\
\hline $\mathrm{OS} \rightarrow \mathrm{PS} \rightarrow \mathrm{CMDs}$ & 0.275 & 0.012 & 23.48 & $<0.001$ \\
\hline $\mathrm{OS} \rightarrow \mathrm{PS} \rightarrow \mathrm{INT} \rightarrow$ CMDs & 0.134 & 0.022 & 5.97 & $<0.001$ \\
\hline \multicolumn{5}{|l|}{ SES } \\
\hline $\mathrm{SES} \rightarrow \mathrm{HS} \rightarrow \mathrm{CMDs}$ & 0.060 & 0.014 & 4.22 & $<0.001$ \\
\hline $\mathrm{SES} \rightarrow \mathrm{PS} \rightarrow \mathrm{CMDs}$ & -0.179 & 0.036 & -4.96 & $<0.001$ \\
\hline $\mathrm{SES} \rightarrow \mathrm{INT} \rightarrow \mathrm{CMDs}$ & 0.021 & 0.027 & 0.79 & 0.429 \\
\hline $\mathrm{SES} \rightarrow \mathrm{RS} \rightarrow \mathrm{CMDs}$ & 0.001 & 0.002 & 0.38 & 0.701 \\
\hline $\mathrm{SES} \rightarrow \mathrm{HS} \rightarrow \mathrm{PS} \rightarrow \mathrm{CMDs}$ & 0.060 & 0.014 & 4.22 & $<0.001$ \\
\hline $\mathrm{SES} \rightarrow \mathrm{RS} \rightarrow \mathrm{PS} \rightarrow \mathrm{CMDs}$ & 0.012 & 0.025 & 0.48 & 0.629 \\
\hline $\mathrm{SES} \rightarrow \mathrm{OS} \rightarrow \mathrm{PS} \rightarrow \mathrm{CMDs}$ & -0.015 & 0.015 & -1.00 & 0.318 \\
\hline $\mathrm{SES} \rightarrow \mathrm{HS} \rightarrow \mathrm{INT} \rightarrow \mathrm{CMDs}$ & -0.015 & 0.008 & -1.88 & 0.060 \\
\hline $\mathrm{SES} \rightarrow \mathrm{PS} \rightarrow \mathrm{INT} \rightarrow \mathrm{CMDs}$ & -0.087 & 0.022 & -3.96 & $<0.001$ \\
\hline $\mathrm{SES} \rightarrow \mathrm{RS} \rightarrow \mathrm{INT} \rightarrow \mathrm{CMDs}$ & 0.001 & 0.002 & 0.49 & 0.625 \\
\hline $\mathrm{SES} \rightarrow \mathrm{HS} \rightarrow \mathrm{RS} \rightarrow \mathrm{CMDs}$ & 0.001 & 0.001 & -0.42 & 0.673 \\
\hline $\mathrm{SES} \rightarrow \mathrm{HS} \rightarrow \mathrm{RS} \rightarrow \mathrm{PS} \rightarrow \mathrm{CMDs}$ & -0.008 & 0.006 & -1.37 & 0.170 \\
\hline $\mathrm{SES} \rightarrow \mathrm{HS} \rightarrow \mathrm{OS} \rightarrow \mathrm{PS} \rightarrow \mathrm{CMDs}$ & 0.003 & 0.003 & 0.93 & 0.351 \\
\hline $\mathrm{SES} \rightarrow \mathrm{HS} \rightarrow \mathrm{PS} \rightarrow \mathrm{INT} \rightarrow \mathrm{CMDs}$ & 0.029 & 0.009 & 3.31 & 0.001 \\
\hline
\end{tabular}


Table 4. Cont.

\begin{tabular}{|c|c|c|c|c|}
\hline Paths & SFL & SE & Est/SE ${ }^{a}$ & $p$-Value ${ }^{b}$ \\
\hline $\mathrm{SES} \rightarrow \mathrm{RS} \rightarrow \mathrm{PS} \rightarrow \mathrm{INT} \rightarrow \mathrm{CMDs}$ & 0.006 & 0.012 & 0.48 & 0.629 \\
\hline $\mathrm{SES} \rightarrow \mathrm{OS} \rightarrow \mathrm{PS} \rightarrow \mathrm{INT} \rightarrow \mathrm{CMDs}$ & -0.007 & 0.008 & -0.99 & 0.325 \\
\hline $\mathrm{SES} \rightarrow \mathrm{HS} \rightarrow \mathrm{RS} \rightarrow \mathrm{INT} \rightarrow \mathrm{CMDs}$ & -0.001 & 0.001 & -1.06 & 0.289 \\
\hline $\mathrm{SES} \rightarrow \mathrm{HS} \rightarrow \mathrm{RS} \rightarrow \mathrm{PS} \rightarrow \mathrm{INT} \rightarrow \mathrm{CMDs}$ & -0.004 & 0.003 & -1.37 & 0.171 \\
\hline $\mathrm{SES} \rightarrow \mathrm{HS} \rightarrow \mathrm{OS} \rightarrow \mathrm{PS} \rightarrow \mathrm{INT} \rightarrow \mathrm{CMDs}$ & 0.002 & 0.002 & 0.92 & 0.356 \\
\hline \multicolumn{5}{|l|}{ PS } \\
\hline $\mathrm{PS} \rightarrow \mathrm{INT} \rightarrow \mathrm{CMDs}$ & 0.249 & 0.040 & 6.22 & $<0.001$ \\
\hline \multicolumn{5}{|l|}{ COL } \\
\hline $\mathrm{COL} \rightarrow \mathrm{PS} \rightarrow \mathrm{CMDs}$ & 0.135 & 0.006 & 20.80 & $<0.001$ \\
\hline $\mathrm{COL} \rightarrow \mathrm{INT} \rightarrow \mathrm{CMDs}$ & -0.034 & 0.019 & -1.78 & 0.075 \\
\hline $\mathrm{COL} \rightarrow \mathrm{SES} \rightarrow \mathrm{CMDs}$ & 0.135 & 0.006 & 20.80 & $<0.001$ \\
\hline $\mathrm{COL} \rightarrow \mathrm{SES} \rightarrow \mathrm{HS} \rightarrow \mathrm{CMDs}$ & 0.026 & 0.006 & 4.21 & $<0.001$ \\
\hline $\mathrm{COL} \rightarrow \mathrm{SES} \rightarrow \mathrm{PS} \rightarrow \mathrm{CMDs}$ & -0.079 & 0.016 & -4.93 & $<0.001$ \\
\hline $\mathrm{COL} \rightarrow \mathrm{PS} \rightarrow \mathrm{INT} \rightarrow \mathrm{CMDs}$ & 0.066 & 0.011 & 5.92 & $<0.001$ \\
\hline $\mathrm{COL} \rightarrow \mathrm{SES} \rightarrow \mathrm{INT} \rightarrow \mathrm{CMDs}$ & 0.009 & 0.012 & 0.79 & 0.429 \\
\hline $\mathrm{COL} \rightarrow \mathrm{SES} \rightarrow \mathrm{RS} \rightarrow \mathrm{CMDs}$ & 0.000 & 0.001 & 0.38 & 0.702 \\
\hline $\mathrm{COL} \rightarrow \mathrm{SES} \rightarrow \mathrm{HS} \rightarrow \mathrm{PS} \rightarrow \mathrm{CMDs}$ & 0.026 & 0.006 & 4.21 & $<0.001$ \\
\hline $\mathrm{COL} \rightarrow \mathrm{SES} \rightarrow \mathrm{RS} \rightarrow \mathrm{PS} \rightarrow \mathrm{CMDs}$ & 0.005 & 0.011 & 0.48 & 0.629 \\
\hline $\mathrm{COL} \rightarrow \mathrm{SES} \rightarrow \mathrm{OS} \rightarrow \mathrm{PS} \rightarrow \mathrm{CMDs}$ & -0.007 & 0.007 & -1.00 & 0.319 \\
\hline $\mathrm{COL} \rightarrow \mathrm{SES} \rightarrow \mathrm{HS} \rightarrow \mathrm{INT} \rightarrow \mathrm{CMDs}$ & -0.007 & 0.004 & -1.88 & 0.060 \\
\hline $\mathrm{COL} \rightarrow \mathrm{SES} \rightarrow \mathrm{PS} \rightarrow \mathrm{INT} \rightarrow \mathrm{CMDs}$ & -0.038 & 0.010 & -3.95 & $<0.001$ \\
\hline $\mathrm{COL} \rightarrow \mathrm{SES} \rightarrow \mathrm{RS} \rightarrow \mathrm{INT} \rightarrow \mathrm{CMDs}$ & 0.000 & 0.001 & 0.49 & 0.625 \\
\hline $\mathrm{COL} \rightarrow \mathrm{SES} \rightarrow \mathrm{HS} \rightarrow \mathrm{RS} \rightarrow \mathrm{CMDs}$ & 0.000 & 0.001 & -0.42 & 0.673 \\
\hline $\mathrm{COL} \rightarrow \mathrm{SES} \rightarrow \mathrm{HS} \rightarrow \mathrm{RS} \rightarrow \mathrm{PS} \rightarrow \mathrm{CMDs}$ & -0.004 & 0.003 & -1.37 & 0.170 \\
\hline $\mathrm{COL} \rightarrow \mathrm{SES} \rightarrow \mathrm{HS} \rightarrow \mathrm{OS} \rightarrow \mathrm{PS} \rightarrow \mathrm{CMDs}$ & 0.001 & 0.002 & 0.93 & 0.351 \\
\hline $\mathrm{COL} \rightarrow \mathrm{SES} \rightarrow \mathrm{HS} \rightarrow \mathrm{PS} \rightarrow \mathrm{INT} \rightarrow \mathrm{CMDs}$ & 0.013 & 0.004 & 3.30 & 0.001 \\
\hline $\mathrm{COL} \rightarrow \mathrm{SES} \rightarrow \mathrm{RS} \rightarrow \mathrm{PS} \rightarrow \mathrm{INT} \rightarrow \mathrm{CMDs}$ & 0.003 & 0.005 & 0.48 & 0.629 \\
\hline $\mathrm{COL} \rightarrow \mathrm{SES} \rightarrow \mathrm{OS} \rightarrow \mathrm{PS} \rightarrow \mathrm{INT} \rightarrow \mathrm{CMDs}$ & -0.003 & 0.003 & -0.99 & 0.325 \\
\hline $\mathrm{COL} \rightarrow \mathrm{SES} \rightarrow \mathrm{HS} \rightarrow \mathrm{RS} \rightarrow \mathrm{INT} \rightarrow \mathrm{CMDs}$ & 0.000 & 0.000 & -1.06 & 0.289 \\
\hline $\mathrm{COL} \rightarrow \mathrm{SES} \rightarrow \mathrm{HS} \rightarrow \mathrm{RS} \rightarrow \mathrm{PS} \rightarrow \mathrm{INT} \rightarrow \mathrm{CMDs}$ & -0.002 & 0.001 & -1.37 & 0.171 \\
\hline $\mathrm{COL} \rightarrow \mathrm{SES} \rightarrow \mathrm{HS} \rightarrow \mathrm{OS} \rightarrow \mathrm{EP} \rightarrow \mathrm{INT} \rightarrow \mathrm{CMDs}$ & 0.001 & 0.001 & 0.92 & 0.356 \\
\hline \multicolumn{5}{|l|}{ HS } \\
\hline $\mathrm{HS} \rightarrow \mathrm{PS} \rightarrow \mathrm{CMDs}$ & 0.281 & 0.012 & 23.79 & $<0.001$ \\
\hline $\mathrm{HS} \rightarrow \mathrm{INT} \rightarrow \mathrm{CMDs}$ & -0.071 & 0.033 & -2.17 & 0.030 \\
\hline $\mathrm{HS} \rightarrow \mathrm{RS} \rightarrow \mathrm{CMDs}$ & -0.002 & 0.006 & -0.43 & 0.668 \\
\hline $\mathrm{HS} \rightarrow \mathrm{RS} \rightarrow \mathrm{PS} \rightarrow \mathrm{CMDs}$ & -0.038 & 0.026 & -1.45 & 0.146 \\
\hline $\mathrm{HS} \rightarrow \mathrm{OS} \rightarrow \mathrm{PS} \rightarrow \mathrm{CMDs}$ & 0.015 & 0.016 & 0.97 & 0.334 \\
\hline $\mathrm{HS} \rightarrow \mathrm{PS} \rightarrow \mathrm{INT} \rightarrow \mathrm{CMDs}$ & 0.136 & 0.023 & 5.93 & $<0.001$ \\
\hline $\mathrm{HS} \rightarrow \mathrm{RS} \rightarrow \mathrm{INT} \rightarrow \mathrm{CMDs}$ & -0.003 & 0.003 & -1.10 & 0.273 \\
\hline $\mathrm{HS} \rightarrow \mathrm{RS} \rightarrow \mathrm{PS} \rightarrow \mathrm{INT} \rightarrow \mathrm{CMDs}$ & -0.019 & 0.013 & -1.46 & 0.144 \\
\hline $\mathrm{HS} \rightarrow \mathrm{OS} \rightarrow \mathrm{PS} \rightarrow \mathrm{INT} \rightarrow \mathrm{CMDs}$ & 0.007 & 0.008 & 0.96 & 0.338 \\
\hline
\end{tabular}

SFL, standardized factor loads; SE, standard error; Est/SE, ratio between SFL estimate and SE; SES, socioeconomic status; INT, intolerance to uncertainty; RS, receiving support; OS, offering support; HS, house-sharing; COL, self-reported race/skin color; PS, perceived stress; CMDs, common mental disorders. ${ }^{a}$ Statistically significant if $-1.96>$ Est $/ \mathrm{SE}>1.96{ }^{\mathrm{b}}$ Statistically significant if $<0.05$

It is to be noted that there was no statistically significant direct effect for CMDs from receiving and offering social support. However, among the specific indirect paths, the greatest effects included receiving low social support $(\lambda=0.442 ; p$-value $<0.001)$, with strong and significant magnitude, and offering high social support $(\lambda=0.275 ; p$-value $<0.001)$, of medium size and significant, both mediated by high stress levels. The medium effects of living alone mediated by high stress level $(\lambda=0.281 ; p$-value $<0.001)$, of high stress level mediated by high level of intolerance to uncertainty $(\lambda=0.249 ; p$-value $<0.001)$, and of low social support mediated by high levels of stress and intolerance to uncertainty $(\lambda=0.214$; $p$-value $<0.001$ ) also stood out (Table 4 ). 


\section{Discussion}

The study evidenced a high prevalence of CMDs in men, which corroborates other findings on the high rates of mental illness in the Brazilian population during the COVID-19 pandemic $[70,71]$. In the pandemic context, no studies analyzing CMDs were identified, hindering comparisons. However, high prevalence values of sadness/depression, anxiety/nervousness, worsening of sleep problems, and panic syndrome were observed in Brazil during the pandemic [70,71]. These feelings experienced by men can be evoked to understand the high prevalence of CMD among them in the pandemic context since the instrument used to assess these minor mental disorders allows the identification of symptoms of anxious and depressive behavior, decreased energy, somatic symptoms, and depressive mood [44-46].

In this study, the high prevalence of CMDs is more pronounced among black-skinned men, higher socioeconomic status, living alone, and higher levels of PS and INT, and these last two factors are the ones most strongly associated with CMDs. Although OS has not presented any direct effect, specific indirect effects, such as receiving low social support and offering high social support, both mediated by high stress levels, were associated with CMDs.

The socioeconomic differences seem to exert an effect on the development of CMDs although the underlying mechanisms of that association are not yet well understood. The effect of higher socioeconomic status on the higher occurrence of CMDs is apparently controversial to what is documented in the literature [72,73], but some aspects can be evoked to understand this finding in this context of the COVID-19 pandemic: (a) the study was carried out in a virtual environment, which contributed to the lower access of men with low socioeconomic status and possible underestimation of CMDs in this stratum; (b) men with higher socioeconomic status may have a better perception of their mental health status due to a better schooling level [72], reflecting higher CMDs rates in a self-reporting questionnaire; (c) due to the restrictions imposed by the COVID-19 pandemic, men with higher socioeconomic status may be experiencing, abruptly and suddenly, more financial deprivation related to business and work, in social relationships, and in their life dynamics, situations that are already part of the daily lives of those with lower socioeconomic status even before the pandemic, and due to the absence of intrinsic reinforcement, they end up in mental distress; and (d) greater fear of poverty is associated with higher stress and anxiety levels among people with higher socioeconomic status during the pandemic, and maintenance of these levels reflects in mental illness [74]. Thus, this finding needs to be researched longitudinally in order to explore the possibilities of the causal link.

The "living alone" factor mediated the effect of SES on the CMDs so that those with higher socioeconomic status presented higher stress levels and higher prevalence of CMDs. These two factors, mediated by the high PS and INT levels, presented considerable indirect effects for CMDs. Living with family members/friends was related to a higher level of intolerance to uncertainty and to more prevalence of CMDs. In this context, although measures of social distancing and quarantine of the population are important for reducing morbidity and mortality due to COVID-19, their effects on the health of the population are undeniable. Regarding mental health, feelings and emotions, such as boredom, loneliness, anger, and sadness, can emerge not only because of the precautionary and control measures imposed but also because of the perception of vulnerability to contagion and risk of illness, especially among those who live alone [75].

The PS and INT factors are very inter-related so that men with higher PS levels had higher INT levels, resulting in greater prevalence of CMDs. The PS level was influenced by several factors, such as lower socioeconomic status, non-black-skinned people, living alone, receiving low social support, and offering high social support. A study carried out with Brazilian parents also identified that PS was the variable most strongly related to the CMD symptoms, showing that the higher the level of perceived stress, the greater the suspicion of these disorders [76]. Several factors have been associated with the occurrence of stress during the pandemic, which include concern about physical health and precautionary and 
disease control measures [76], anger and confusion arising from quarantine and social distancing [75], income reduction [75-77], fear of infection [75], and being part of a risk group for COVID-19 [77].

Regarding the socioeconomic situation of the men, the excess of demands, the fear of income loss, and the holding of the capital power may have contributed to increased stress levels and, consequently, to a higher prevalence of CMDs. This association is an important warning sign to be included in the global public health agenda, in a commitment to promote actions to reduce stress, increase literacy in male mental health for the perception of stress, and self-management of mental health care [78].

INT is a vulnerability factor associated with the development and maintenance of mental disorders [79]. Uncertainty about the future is a potentially stressful condition [80], hence the strong association with the occurrence of CMDs. The study evidenced that INT is negatively associated with mental well-being, especially when mediated by loneliness and fear of COVID-19, which are feelings intensely experienced during the pandemic [81]. Thus, it is necessary to implement actions to promote increased resilience and development and/or strengthening of intrinsic reinforcements to deal with the impacts of regular exposure to uncertain threats.

It is also highlighted that, although there are groups at higher risk, COVID-19 ends up affecting different social segments, and men tend to adhere less to the care measures and to neglect their health [82]. The occurrence and extension of this scenario can be even more impactful when considering social support, whether from the perspective of receiving or offering emotional and instrumental support. Thus, it is indispensable to formulate and strengthen already existing actions to promote psychosocial and emotional support for men in an exercise of citizenship and health care promotion that strengthens socio-affective networks, enabling men to have someone to count on in critical moments like a pandemic.

In addition to the categories of psychological disorders such as stress, other structural categories need to be analyzed in the scenario of impacts on male mental health, such as race/skin color and territory (geographic location and area of residence), since our findings identified that black-skinned men, those with higher socioeconomic status, who lived alone, and with higher levels of stress and intolerance to uncertainty had a higher prevalence of CMDs. Thus, an intersectional perspective needs to be employed as a way of explaining the vulnerabilities, inequalities, inequities, and necropolitics that promote overlapping impacts on the health, quality of life, and well-being of men who belong to marginalized groups, an aspect confirmed in our study when we identified the disparity in economic status among non-black-skinned men.

Although knowledge about the disease is advanced, there are still many gaps. Commonly, guided behaviors are based on scientific evidence, protocols, and guidelines. However, the recommendations themselves present certain degree of uncertainty, which generates doubts and discomfort in the face of the unknown on the part of authorities, health professionals, and the population [83]. Given this scenario, it is necessary to accept the existence of these uncertainties, limitations, and incompleteness in current knowledge. Transparency regarding these issues is a strategy to deal with the unknown in a rational and ethical way. In addition, the relevance of providing information and guidelines as recommended by the health authorities is emphasized as a way to avoid excessive simplifications and the dissemination of easy answers if they do not exist. Thus, gaining trust becomes one of the greatest challenges and ends up fighting mistrust and fake news [84], which intensify the emergence of conspiracy theories, misinformation, and "infodemic" [85-90].

Our study adopted a cross-sectional design and a sampling technique with recruitment by non-probabilistic methods, which limit the causal inference and external validity of the results. In addition to that, participation of men with no access to the interview via the Internet was excluded, which may have over- or under-estimated the prevalence of CMDs in the strata evaluated. 


\section{Conclusions}

The results of this study point out the high prevalence of CMDs in men in the pandemic context and reinforce the need to assess the factors that precede this disease and to replicate the study with women. In addition to that, they endorse the importance of constructing latent variables to measure subjective aspects since three important latent constructs were revealed to be better studied, namely socioeconomic status, intolerance to uncertainty, and social support.

In addition to that, the study allowed identifying a higher prevalence of CMDs among younger men, with lower schooling, black-skinned, without a partner, who lived alone, did not work, with high levels of stress and intolerance to uncertainty, and who received low social support. It was also evidenced that the high levels of stress and intolerance to uncertainty were the factors that presented the strongest direct associations with the occurrence of CMDs.

These findings indicate that stress and intolerance to uncertainty are important factors in understanding mental suffering among men. Dealing with unexpected situations, with the loss of close people and future life perspectives accentuates stress levels, with the consequence of the occurrence and/or worsening of CMD. This situation is even worse in the presence of receiving low social support from close people and/or the government, as this support has an important mitigating effect on mental suffering, being able to resolve the harmful impacts of high psychological demand and the low control over adverse situations.

Thus, the importance of developing mental health promotion policies and actions for male populations is highlighted, considering that intervening in the aspects associated with the occurrence of CMDs is crucial to facing the impacts of the COVID-19 pandemic in the different life dimensions.

Author Contributions: Conceptualization, A.R.d.S. and Á.P.; methodology, validation, formal analysis, investigation, data curation, writing —original draft preparation, writing-review and editing, and visualisation, A.R.d.S., J.R.B.T., E.M.S.P., W.C.M., M.B.S., H.E.F.d.C., É.S.A., R.M.S.F., A.M.d.Q., M.C.d.M., T.N.M., I.F.M.A., J.C.d.S., S.D.d.S., E.L.S.C., L.G.L., R.A.R.d.S., E.S.d.S.C., I.L., S.B., T.M.d.A., M.A.F.d.O., Á.P., W.A. and C.A.d.C.S. All authors have read and agreed to the published version of the manuscript.

Funding: National Funds through FCT—Fundação para a Ciência e Tecnologia, I.P., within CINTESIS, R\&D Unit (reference UIDB/4255/2020) and Escola Superior de Enfermagem do Porto UIDB/4255/2020.

Institutional Review Board Statement: The study was conducted according to the guidelines of the Declaration of Helsinki and the study was approved by the Research Ethics Committee at Universidade Federal da Bahia (decision: 4,087,611; CAAE: 32889420.9.0000.5531) on 8 April 2020.

Informed Consent Statement: Informed consent was obtained from all subjects involved in the study.

Data Availability Statement: The datasets generated during the current study are not publicly available but are available from the corresponding author on reasonable request.

Acknowledgments: To the men who participated in the study. All participants agreed to participate in the study by signing the Informed Consent Form.

Conflicts of Interest: The authors declare no conflict of interest.

\section{References}

1. Dal'Bosco, E.B.; Floriano, L.S.M.; Rangel, A.G.S.S.; Ribas, M.C.; Cavalheiro, A.P.G.; Silva, C.L.D.; Cabral, L.P.A. Coping in mental health during social isolation: Analysis in light of Hildegard Peplau. Rev. Bras. Enferm. 2021, 75, e20201207. [CrossRef]

2. Sousa, A.R.; Teixeira, J.R.B.; Mota, T.N.; Santana, T.D.S.; Santos, S.D.D.; Merces, M.C.D.; Carvalho, E.S.S.; Sousa, Á.F.L. Coping strategies, concerns, and habits of Brazilian men in the COVID-19 context. Rev. Bras. Enferm. 2021, 74, e20210040. [CrossRef]

3. Faro, A.; Bahiano, M.A.; Nakano, T.C.; Reis, C.; Silva, B.F.P.; Vitti, L.S. COVID-19 e saúde mental: A emergência do cuidado. Estud. De Psicol. (Campinas) 2020, 37, 1-14. [CrossRef]

4. Mari, J.J.; Oquendo, M.A. Mental health consequences of COVID-19: The next global pandemic. Trends Psychiatr. Psychother 2020, 42, 219-220. [CrossRef] 
5. Moreira, W.C.; Sousa, A.R.; Nóbrega, M.D.P.S.S. Mental illness in the general population and health professionals during COVID-19: A scoping review. Texto Contexto Enferm. 2020, 29, e20200215. [CrossRef]

6. Paiano, M.; Jaques, A.E.; Nacamura, P.A.B.; Salci, M.A.; Radovanovic, C.A.T.; Carreira, L. Mental health of healthcare professionals in China during the new coronavirus pandemic: An integrative review. Rev. Bras. Enferm. 2020, 73, e20200338. [CrossRef] [PubMed]

7. Ornell, F.; Schuch, J.B.; Sordi, A.O.; Kessler, F.H.P. Pandemic fear" and COVID-19: Mental health burden and strategies. Braz. J. Psychiatr. 2020, 42, 232-235. [CrossRef] [PubMed]

8. Xiang, Y.T.; Yang, Y.; Li, W.; Zhang, L.; Zhang, Q.; Cheung, T.; Ng, C.H. Timely mental health care for the 2019 novel coronavirus outbreak is urgently needed. Lancet Psychiat. 2020, 7, 228-229. [CrossRef]

9. Mamun, M.A.; Griffiths, M.D. First COVID-19 suicide case in Bangladesh due to fear of COVID-19 and xenophobia: Possible suicide prevention strategies. Asian J. Psychiatr. 2020, 51, 102073. [CrossRef]

10. Goyal, K.; Chauhan, P.; Chhikara, K.; Gupta, P.; Singh, M.P. Fear of COVID 2019: First suicidal case in India. Asian J. Psychiatr 2020, 49, 101989. [CrossRef]

11. Gonzalez-Diaz, J.M.; Cano, J.F.; Pereira-Sanchez, V. Psychosocial impact of COVID-19-related quarantine: Reflections after the first case of suicide in Colombia. Cad Saúde Pública 2020, 36, e00117420. [CrossRef]

12. Gonçalves Júnior, J.; de Sales, J.P.; Moreno, M.M.; Rolim-Neto, M.L. The Impacts of SARS-CoV-2 Pandemic on Suicide: A Lexical Analysis. Front. Psychiatr. 2021, 10, 593918. [CrossRef]

13. Sousa, A.R.; Moreira, W.C.; Queiroz, A.M.; Rezende, M.F.; Teixeira, J.R.B.; Merces, M.C.; Silva, A.V.; Camargo, E.L.S. COVID-19 pandemic decrease men's mental health: Background and consequence analysis. J. Bras. Psiquiatr. 2021, 70, 141-148. [CrossRef]

14. Bao, Y.; Sun, Y.; Meng, S.; Shi, J.; Lu, L. 2019-nCoV epidemic: Address mental health care to empower society. Lancet 2020, 395, e37-e38. [CrossRef]

15. Dubey, S.; Biswas, P.; Ghosh, R.; Chatterjee, S.; Dubey, M.J.; Chatterjee, S.; Lahiri, D.; Lavie, C.J. Psychosocial impact of COVID-19. Diabetes Metab. Syndr. 2020, 14, 779-788. [CrossRef]

16. Wu, T.; Jia, X.; Shi, H.; Niu, J.; Yin, X.; Xie, J.; Wang, X. Prevalence of mental health problems during the COVID-19 pandemic: A systematic review and meta-analysis. J. Affect. Disord. 2021, 15, 91-98. [CrossRef] [PubMed]

17. Cui, L.; Wang, X.; Wang, H. Challenges facing coronavirus disease 2019: Psychiatric services for patients with mental disorders. Psychiatr. Clin. Neurosci. 2020, 74, 371-372. [CrossRef]

18. World Health Organization (WHO). Depression and Other Common Mental Disorders: Global Health Estimates. 2017. Available online: www.who.int/mental_health/management/depression/prevalence_global_health_estimates/en/(accessed on 30 April 2021).

19. Souza, I.M.; Sousa, J.P.M. Brazil: World leader in anxiety and depression rates. Rev. Bras. De Psiquiatr. 2017, 39, 384. [CrossRef]

20. Smolen, J.R.; Araújo, E.M.; Oliveira, N.F.; Araújo, T.M. Intersectionality of Race, Gender, and Common Mental Disorders in Northeastern Brazil. Ethn. Dis. 2018, 28, 207-214. [CrossRef] [PubMed]

21. Morriss, J.; Christakou, A.; van Reekum, C.M. Nothing is safe: Intolerance of uncertainty is associated with compromised fear extinction learning. Biol. Psychol. 2016, 121, 187-193. [CrossRef] [PubMed]

22. Holaway, R.M.; Heimberg, R.G.; Coles, M.E. A comparison of intolerance of uncertainty in analogue obsessive-compulsive disorder and generalized anxiety disorder. J. Anxiety Disord. 2006, 20, 158-174. [CrossRef]

23. Hollingsworth, D.W.; Gauthier, J.M.; McGuire, A.P.; Peck, K.R.; Hahn, K.S.; Connolly, K.M. Intolerance of uncertainty mediates symptoms of PTSD and depression in African American veterans with comorbid PTSD and substance use disorders. J. Black Psychol. 2018, 44, 667-688. [CrossRef]

24. McEvoy, P.M.; Mahoney, A.E.J. Achieving certainty about the structure of intolerance of uncertainty in a treatment-seeking sample with anxiety and depression. J. Anxiety Disord. 2011, 25, 112-122. [CrossRef] [PubMed]

25. Tolin, D.F.; Abramowitz, J.S.; Brigidi, B.D.; Foa, E.B. Intolerance of Uncertainty in obsessive-compulsive disorder. J. Anxiety Disord. 2003, 17, 233-242. [CrossRef]

26. Satici, B.; Saricali, M.; Satici, S.A.; Griffiths, M.D. Intolerance of Uncertainty and Mental Wellbeing: Serial Mediation by Rumination and Fear of COVID-19. Int. J. Ment. Health Addict. 2020, 15, 1-12. [CrossRef]

27. Anselmi, L.; Barros, F.C.; Minten, G.C.; Gigante, D.P.; Horta, B.L.; Victora, C.G. Prevalência e determinantes precoces dos transtornos mentais comuns na coorte de nascimentos de 1982, Pelotas, RS. Rev. De Saúde Pública 2008, 42, 26-33. [CrossRef]

28. Mattos, A.I.S.; de Araújo, T.M.; de Almeida, M.M.G. Almeida Interaction between demand-control and social support in the occurrence of common mental disorders. Rev. De Saúde Pública 2017, 51, 48. [CrossRef]

29. Ribeiro, I.B.d.S.; Correa, M.M.; Oliveira, G.; Cade, N.V. Common mental disorders and socioeconomic status in adolescents of ERICA. Rev. De Saúde Pública 2020, 54, 4. [CrossRef] [PubMed]

30. Patel, V.; Kleinman, A. Poverty and common mental disorders in developing countries. Bull. World Health Organ. 2003, 81, 609-615.

31. Coutinho, L.M.S.; Matijasevich, A.; Scazufca, M.; Meneses, P.R. Prevalência de transtornos mentais comuns e contexto social: Análise multinível do São Paulo Ageing \& Health Study (SPAH). Cad. Saude Publica 2014, 30, 1875-1883. [CrossRef]

32. Jacob, L.; Haro, J.M.; Koyanagi, A. Relationship between living alone and common mental disorders in the 1993, 2000 and 2007 National Psychiatric Morbidity Surveys. PLoS ONE 2019, 14, e0215182. [CrossRef] [PubMed] 
33. World Health Organization. WHO Coronavirus (COVID-19) Dashboard. 2021. Available online: https://covid19.who.int/ (accessed on 14 September 2021).

34. Brasil Ministério da Saúde (BR). Boletim Epidemiológico Especial. Doença Pelo Coronavírus COVID-19. Brasília, DF (BR): MS, 2021. Available online: https://www.gov.br/saude/pt-br/media/pdf/2021/outubro/01/boletim_epidemiologico_covid_82.pdf (accessed on 14 September 2021).

35. Brasil Ministério da Saúde (BR). Boletim Epidemiológico Especial. Doença Pelo Coronavírus COVID-19. Brasília, DF (BR): MS, 2020. Available online: http://saude.gov.br/images/pdf/2020/July/15/Boletim-epidemiologico-COVID-22.pdf (accessed on 30 April 2021).

36. Peckham, H.; de Gruijter, N.M.; Raine, C.; Radziszewska, A.; Ciurtin, C.; Wedderburn, L.R.; Rosser, E.C.; Webb, K.; Deakin, C.T. Male sex identified by global COVID-19 meta-analysis as a risk factor for death and ITU admission. Nat. Commun. 2020, 11, 1-10. [CrossRef] [PubMed]

37. Gorbalenya, A.E.; Baker, S.C.; Baric, R.S.; Groot, R.J.; Drosten, C.; Gulyaeva, A.A.; Ziebuhr, J. The species Severe acute respiratory syndrome-related coronavirus: Classifying 2019-nCoV and naming it SARS-CoV-2. Nat. Microbiol. 2020, 5, 536-544. [CrossRef]

38. Windsor, L.C.; Reinhardt, G.Y.; Windsor, A.J.; OstergardI, R.; Allen, S.; Burns, C.; Giger, J.; Wood, R. Gender in the time of COVID-19: Evaluating national leadership and COVID-19 fatalities. PLoS ONE 2020, 15, e0244531. [CrossRef]

39. Tibubos, A.N.; Otten, D.; Ernst, M.; Beutel, M.E. A Systematic Review on Sex- and Gender-Sensitive Research in Public Mental Health during the First Wave of the COVID-19 Crisis. Front. Psychiatr. 2021, 12, 712492. [CrossRef]

40. Seidler, Z.E.; Dawes, A.J.; Rice, S.M.; Oliffe, J.L.; Dhillon, H.M. The role of masculinity in men's help-seeking for depression: A systematic review. Clin. Psychol. Rev. 2016, 49, 106-118. [CrossRef]

41. Sousa, A.R.; Santana, T.S.; Moreira, W.C.; Sousa, Á.F.L.; Carvalho, E.S.S.; Craveiro, I. Emoções e estratégias de coping de homens à pandemia da covid-19 no Brasil. Texto E Contexto Enferm. 2020, 29, e20200248. [CrossRef]

42. Núcleo de Informação e Coordenação do Ponto BR (NIC. br). Pesquisa Sobre O Uso Das Tecnologias De Informação E Comunicação: Pesquisa TIC Domicílios, ano 2019: Tabelas. São Paulo: 2020. Available online: http:/ / cetic.br/pt/arquivos/domicilios/20 19/individuos/\#tabelas (accessed on 30 April 2021).

43. Biernacki, P.; Waldorf, D. Snowball sampling: Problems and techniques of chain referral sampling. Sociol. Methods Res. 1981, 10, 141-163. [CrossRef]

44. Mari, J.J.; Williams, P. A validity study of a psychiatric screening questionnaire (SRQ-20) in primary care in the city of Sao Paulo. Br. J. Psychiatr. 1986, 148, 23-26. [CrossRef]

45. Santos, K.O.B.; Araújo, T.M.; Sousa Pinho, P.; Silva, A.C.C. Avaliação de um instrumento de mensuração de morbidade psíquica: Estudo de validação do Self-Reporting Questionnaire (SRQ-20). Rev. Baiana De Saúde Pública 2010, 34, 544. [CrossRef]

46. Santos, K.O.B.; Carvalho, F.M.; Araújo, T.M. Consistência interna do self-reporting questionnaire-20 em grupos ocupacionais. Rev. Saude Publica 2016, 50, 6. [CrossRef]

47. Cohen, S.; Kamarck, T.; Mermelstein, R. A global measure of perceived stress. J. Health Soc. Behav. 1983, 24, 385-396. [CrossRef] [PubMed]

48. Luft, C.D.; Sanches, S.O.; Mazo, G.Z.; Andrade, A. Versão brasileira da Escala de Estresse Percebido: Tradução e validação para idosos. Rev. Saúde Pública 2007, 41, 606-615. [CrossRef] [PubMed]

49. Machado, W.L.; Damásio, B.F.; Borsa, F.C.; Silva, J.P. Dimensionalidade da Escala de Estresse Percebido (Perceived Stress Scale, PSS10) em uma amostra de professores. Psicol. Reflex. Crit. 2014, 27, 38-43. [CrossRef]

50. Ma, Y.; Rosenheck, R.; He, H. Psychological stress among health care professionals during the 2019 novel coronavirus disease Outbreak: Cases from online consulting customers. Intensive Crit. Care Nurs. 2020, 61, 102905. [CrossRef]

51. Freeston, M.H.; Rheaume, J.; Letarte, H.; Dugas, M.J.; Ladouceur, R. Why Do People Worry? Personal. Individ. Differ. 1994, 17, 791-802. [CrossRef]

52. Carleton, R.N.; Norton, M.A.; Asmundson, G.J. Fearing the unknown: A short version of the Intolerance of Uncertainty Scale. J. Anxiety Disord. 2007, 21, 105-117. [CrossRef] [PubMed]

53. Kretzmann, R.P. Intolerance of Uncertainty Scale (IUS-12) Para Uso No Brasil: Adaptação Transcultural E Propriedades Psicométricas. Ph.D. Thesis, Universidade Federal do Rio Grande do Sul, Porto Alegre, RS, Brazil, 2018.

54. Kretzmann, R.P.; Gauer, G. Psychometric properties of the Brazilian Intolerance of Uncertainty Scale-Short Version (IUS-12). Trends Psychiatr. Psychother 2020, 42, 129-137. [CrossRef] [PubMed]

55. Norton, P.J. A psychometric analysis of the Intolerance of Uncertainty Scale among four racial groups. J. Anxiety Disord. 2005, 6, 699-707. [CrossRef]

56. Yao, N.; Qian, M.; Jiang, Y.; Elhai, J.D. The Influence of Intolerance of Uncertainty on Anxiety and Depression Symptoms in Chinese-speaking Samples: Structure and Validity of The Chinese Translation of The Intolerance of Uncertainty Scale. J. Pers. Assess. 2021, 103, 406-415. [CrossRef] [PubMed]

57. Bottesi, G.; Noventa, S.; Freeston, M.H.; Ghisi, M. Seeking certainty about Intolerance of Uncertainty: Addressing old and new issues through the Intolerance of Uncertainty Scale-Revised. PLoS ONE 2019, 14, e0211929. [CrossRef]

58. Shakespeare-Finch, J.; Obst, P.L. The development of the 2-Way Social Support Scale: A measure of giving and receiving emotional and instrumental support. J. Pers. Assess. 2011, 93, 483-490. [CrossRef] [PubMed] 
59. Bastianello, M.R. Implicações Do Otimismo, Autoestima E Suporte Social Percebido Na Qualidade De Vida De Mulheres Com Câncer De Mama [Implications of Optimism, Self Esteem and Perceived Social Support on Quality of Life of Women with Breast Cancer]. Ph.D. Thesis, Universidade Federal do Rio Grande do Sul, Porto Alegre, RS, Brazil, 2015.

60. Glymour, M.M.; Greenland, S. Causal diagrams. Ch. 12. In Modern Epidemiology, 3rd ed.; Rothman, K.J., Greenland, S., Lash, T.L., Eds.; Lippincott: Philadelphia, PA, USA, 2008.

61. Hernán, M.A.; Robins, J.M. Causal Inference: What If; Chapman \& Hall/CRC: Boca Raton, FL, USA, 2020.

62. Cortes, T.R.; Faerstein, E.S.; Claudio, J. Utilização de diagramas causais em epidemiologia: Um exemplo de aplicação em situação de confusão. Cad. Saúde Pública 2016, 32, e00103115. [CrossRef] [PubMed]

63. Werneck, G.L. Diagramas causais: A epidemiologia brasileira de volta para o futuro. Cad. De Saúde Pública 2016, 32 , e00120416. [CrossRef]

64. Marôco, J. Análise De Equações Estruturais-Fundamentos Teóricos, 2nd ed.; Software e Aplicações: Lisboa, Portugal, 2014.

65. Marsh, H.W.; Muthén, B.; Asparouhov, T.; Lüdtke, O.; Robitzsch, A.; Morin, A.J.S.; Trautwein, U. Exploratory structural equation modeling, integrating CFA and EFA: Application to students' evaluations of university teaching. Struct. Equ. Modeling 2009, 16, 439-476. [CrossRef]

66. Hair, J.F.J.; Black, W.C.; Babin, B.J.; Anderson, R.E.; Tatham, R.L. Análise Multivariada De Dados, 6th ed.; Bookman: Porto Alegre, RS, Brazil, 2009.

67. Reichenheim, M.E.; Hökerberg, Y.H.M.; Moraes, C.L. Assessing construct structural validity of epidemiological measurement tools: A seven-step roadmap. Cad. Saúde Pública 2014, 30, 927-939. [CrossRef]

68. Kline, R.B. Principles and Practice of Structural Equation Modeling; Guilford Press: New York, NY, USA, 2015.

69. Brown, T.A. Methodology in the social sciences. In Confirmatory Factor Analysis for Applied Research, 2nd ed.; Guilford Press: New York, NY, USA, 2015.

70. Barros, A.J.D.; Victora, C.G.; Menezes, A.M.B.; Horta, B.L.; Hartwig, F.; Victora, G.; Pellanda, L.C.; A Dellagostin, O.; Struchiner, C.J.; Burattini, M.N.; et al. Social distancing patterns in nine municipalities of Rio Grande do Sul, Brazil: The Epicovid19/RS study. Rev. Saúde Pública 2020, 54, 75. [CrossRef]

71. Lipp, M.E.N.; Lipp, L.M.N. Stress e transtornos mentais durante a pandemia da COVID-19 no Brasil. Rev. Da Acad. Paul. De Psicol. 2020, 40, 180-191.

72. Dorner, T.E.; Mittendorfer-Rutz, E. Socioeconomic inequalities in treatment of individuals with common mental disorders regarding subsequent development of mental illness. Soc. Psychiatr. Psychiatr. Epidemiol. 2017, 52, 1015-1022. [CrossRef] [PubMed]

73. Jokela, M.; Batty, G.; Vahtera, J.; Elovainio, M.; Kivimäki, M. Socioeconomic inequalities in common mental disorders and psychotherapy treatment in the UK between 1991 and 2009. Br. J. Psychiatr. 2013, 202, 115-120. [CrossRef]

74. Salameh, P.; Hajj, A.; A Badro, D.; Selwan, C.A.; Aoun, R.; Sacre, H. Mental Health Outcomes of the COVID-19 Pandemic and a Collapsing Economy: Perspectives from a Developing Country. Psychiatr. Res. 2020, 294, 113520. [CrossRef]

75. Brooks, S.K.; Webster, R.K.; Smith, L.E.; Woodland, L.; Wessely, S.; Greenberg, N.; Rubin, G.J. The psychological impact of quarantine and how to reduce it: Rapid review of the evidence. Lancet 2020, 395, 912-920. [CrossRef]

76. Riter, H.S.; Almeida, M.L.; Vescovi, G.; Marques, F.M.; Pedrotti, B.G.; Mallmann, M.Y.; Pieta, M.A.M.; Frizzo, G.B. Symptoms of Common Mental Disorders in Brazilian Parents During the COVID-19 Pandemic: Associated Factors. Psychol. Stud. 2021, 66, 270-279. [CrossRef] [PubMed]

77. Duarte, M.Q.; Santo, M.A.S.; Lima, C.P.; Giordani, J.P.; Trentini, C.M. COVID-19 e os impactos na saúde mental: Uma amostra do Rio Grande do Sul, Brasil. Cien Saude Colet 2020, 25, 3401-3412. [CrossRef] [PubMed]

78. Sousa, A.R.; Alves, G.V.; Queiroz, A.M.; Florêncio, R.M.S.; Moreira, W.C.; Nóbrega, M.D.P.S.S.; Teixeira, E.; Rezende, M.F. Men's mental health in the COVID-19 pandemic: Is there a mobilization of masculinities? Rev. Bras. Enferm. 2021, 74, e20200915. [CrossRef]

79. Angehrn, A.; Krakauer, R.L.; Carleton, R.N. The Impact of Intolerance of Uncertainty and Anxiety Sensitivity on Mental Health Among Public Safety Personnel: When the Uncertain is UnavoidableInt. J. Cogn. 2020, 44, 919-930. [CrossRef]

80. Giusti, L.; Salza, A.; Mammarella, S.; Bianco, D.; Ussorio, D.; Casacchia, M.; Roncone, R. Everything Will Be Fine. Duration of Home Confinement and "All-or-Nothing" Cognitive Thinking Style as Predictors of Traumatic Distress in Young University Students on a Digital Platform During the COVID-19 Italian Lockdown. Front. Psychiatr. 2020, 11, 574812. [CrossRef]

81. Rehman, S.U.; Ullah, R.; Imran, M.; Iqbal, K.; Saleem, Z.; Khattak, S.R. Intolerance of Uncertainty and Mental Well-being: Important Role of Loneliness and Fear of COVID-19: Evidence from Higher Educational Institutions. Multicult. Educ. 2021, 7, 147-154. [CrossRef]

82. Alves, A.A.M.; Rodrigues, N.F.R. Determinantes sociais e econômicos da Saúde Mental. Rev. Port. Saúde Pública 2010, 28 , 127-131. [CrossRef]

83. Sousa, A.R.; Araújo, I.F.M.; Borges, C.C.L.; Oliveira, J.A.; Almeida, M.S.; Caribé, W.; Junior, F.J.N.S. Men's health in the covid-19 pandemic: Brazilian panorama. Rev. Baiana Enferm. 2021, 35, e38683. [CrossRef]

84. Botton, A.; Cúnico, S.D.; Strey, M.N. Diferenças de gênero no acesso aos serviços de saúde: Problematizações obrigatórias. Mudanças-Psicol. Da Saúde 2017, 25, 67-72. [CrossRef]

85. Sousa, A.R.; Queiroz, A.M.; Florêncio, R.M.S.; Alves, G.V.; Pedreira, L.C.; Teixeira, E. Sentidos e significados atribuídos por homens ao vivido na pandemia da Covid-19. Rev. Esc. Enferm. USP 2021, 55, e03763. [CrossRef] 
86. Moreira, W.C.; Sousa, K.H.J.F.; Sousa, A.R.; Santana, T.S.; Zeitoune, R.C.G.; Nóbrega, M.P.S.S. Mental health interventions implemented in the COVID-19 pandemic: What is the evidence? Rev. Bras. Enferm. 2021, 74, e20200635. [CrossRef]

87. Moreira, W.C.; Nóbrega, M.P.S.S.; Lima, F.P.S.; Lago, E.C.; Lima, M.O. Effects of the association between spirituality, religiosity and physical activity on health/mental health: A sistematic review. Rev. Esc. Enferm. USP 2020, 54, e03631. [CrossRef] [PubMed]

88. Romiti, G.F.; Talerico, G. Embracing the Uncertainty: An Important Lesson from COVID-19. J. Gen. Intern. Med. 2021, 36, 3562-3564. [CrossRef] [PubMed]

89. Vasconcellos-Silva, P.R.; Castiel, L.D. COVID-19, as fake news e o sono da razão comunicativa gerando monstros: A narrativa dos riscos e os riscos das narrativas. Cad. Saúde Pública 2020, 36, e00101920. [CrossRef] [PubMed]

90. de Sousa, F.L.; Teixeira, J.R.B.; Lua, I.; Souza, F.D.O.; Ferreira, A.J.F.; Schneider, G.; de Carvalho, H.E.F.; de Oliveira, L.B.; Lima, S.V.M.A.; de Sousa, A.R.; et al. Determinants of COVID-19 Vaccine Hesitancy in Portuguese-Speaking Countries: A Structural Equations Modeling Approach. Vaccines 2021, 9, 1167. [CrossRef] 